\title{
Biologia reprodutiva de Ligia exotica (Crustacea, Isopoda, Ligiidae) em Rio Grande, Rio Grande do Sul, Brasil
}

\author{
Elis R. C. Lopes ${ }^{1}$, Juliana R. Blasina², Luiz F. C. Dumont ${ }^{1} \&$ Fernando D’Incao $^{1}$
}

1. Programa de Pós-graduação em Oceanografia Biológica, Departamento de Oceanografia, Fundação Universidade Federal do Rio Grande, Avenida Itália, Km 8, 96201-900 Rio Grande, RS, Brasil.

2. Programa de Pós-graduação em Ciências Fisiológicas, Fisiologia Animal Comparada, Departamento de Ciências Fisiológicas, Fundação Universidade Federal do Rio Grande.

\begin{abstract}
Reproductive biology of Ligia exotica (Crustacea, Isopoda, Ligiidae) in Rio Grande, Rio Grande do Sul State, Brazil. Aiming to elucidate some aspects of the reproductive biology of Ligia exotica Roux, 1828, two populations inhabiting the Estuary of the Patos Lagoon (West Breakwater of Rio Grande Channel and Leonidio Island) were analyzed. Sampling was performed fortnightly, from summer/2003 to winter/2004. Animals were collected manually during one hour. The reproductive season of the species occurred from October to June. No ovigerous females were observed from July to September. In West Breakwater of Rio Grande, 5,376 individuals were captured (1,494 juvenile, 1,748 males and 2,134 females, in which 245 were ovigerous). Sex ratio estimated was 0.78 (M:F). To perform fecundity analysis, 178 ovigerous females with intact marsupium were analyzed. Total length of these females varied from 20.73 to $34.3 \mathrm{~mm}$, and the number of eggs-embryos ranged from 33 to 142 . The mean length of sexual maturity of females was $24.65 \mathrm{~mm}$ and the mean number of eggs-embryos was 88.0. In Leonidio Island, 5,519 animals were collected (510 juvenile, 1,956 males and 3,053 females, from which 129 were ovigerous). The sex ratio was 0.68 (M:F). While the lowest percentages of ovigerous females were found from September to May, the highest percentage of ovigerous female was observed at the end of March. In this location, 101 ovigerous females were analyzed, with total length varying from 17.62 to $28.61 \mathrm{~mm}$, and the number egg-embryos ranged from 25 to 113 . The mean length of sexual maturity of females was $21.43 \mathrm{~mm}$ and the mean number of eggs-embryos was 73.8 .
\end{abstract}

KEYWORDS. Isopoda, Ligia exotica, reproduction, Estuary of the Patos Lagoon, Brazil.

RESUMO. Com o objetivo de elucidar alguns aspectos da biologia reprodutiva de Ligia exotica Roux, 1828, duas populações que habitam o Estuário da Lagoa dos Patos (Molhe Oeste da Barra de Rio Grande e Ilha do Leonídeo) foram analisadas. A amostragem foi realizada quinzenalmente entre o verão/2003 e o inverno/2004. Os animais foram coletados manualmente durante uma hora. $\mathrm{O}$ período reprodutivo da espécie foi registrado para os meses de outubro a junho. Nenhuma fêmea ovígera foi observada de julho a setembro. No Molhe Oeste da Barra de Rio Grande, 5.376 indivíduos foram capturados (1.494 juvenis, 1.748 machos e 2.134 fêmeas, das quais 245 eram ovígeras). A proporção sexual estimada foi 0,78 (M:F). Para a análise da fecundidade, 178 fêmeas ovígeras com o marsúpio intacto foram analisadas. O comprimento total destas fêmeas variou entre 20,73 a $34,3 \mathrm{~mm}$, e o número de ovos-embriões variaram de 33 a 142. O comprimento médio de primeira maturação sexual das fêmeas foi 24,65 mm e o número médio de ovosembriões foi 88. Na Ilha do Leonídeo, 5.519 animais foram coletados (510 juvenis, 1.956 machos e 3.053 fêmeas, das quais 129 eram ovígeras). A proporção sexual foi 0,68 (M:F). Pequenas porcentagens de fêmeas ovígeras foram encontradas de setembro a maio, sendo a mais alta porcentagem observada no final de março. Neste local, 101 fêmeas ovígeras foram analisadas, com o comprimento total variando entre 17,62 a $28,61 \mathrm{~mm}$ e o número de ovos-embriões entre 25 e 113 . O comprimento médio de primeira maturação sexual das fêmeas e o número médio de ovos-embriões foram, respectivamente, $21,43 \mathrm{~mm}$ e 73,8 .

PALAVRAS-CHAVE. Isopoda, Ligia exotica, reprodução, Estuário da Lagoa dos Patos, Brasil.

Os isópodos da subordem Oniscidea são considerados detritívoros e, segundo Schultz (1977), são componentes importantes da fauna entre marés, pois se alimentam da vegetação decomposta trazida por ventos e ondas e das algas que se desenvolvem nessa região. Representam também uma fonte de alimentação para outros animais, constituindo um importante elo na cadeia trófica (SutTon, 1980).

O gênero Ligia Fabricius, 1798 é composto por cerca de 30 espécies de isópodos que se distribuem por regiões quentes e temperadas do globo, habitando áreas rochosas supralitorais (CAREFOOT \& TAYLOR, 1995; CAREFOOT et al., 1998). Ligia exotica Roux, 1828 é uma espécie cosmopolita e, no continente americano, pode ser encontrada da Carolina do Norte ao sul do Brasil e da Califórnia ao Chile (Lemos de CAstro, 1971). No Brasil, a espécie foi registrada para o Rio de Janeiro (SouZA-KuRY, 1998) e para o Rio Grande do Sul (SouzA, 1998).
Entre as espécies do gênero, L. exotica vem sendo alvo de muitos estudos no que diz respeito aos aspectos fisiológicos (HariYama et al., 1993; Tsai et al., 1997; 1998; HaRIYAMA et al., 2001; Hama et al., 2003; YAMAGISHI et al., 2004), mas quanto aos aspectos reprodutivos, a maioria dos trabalhos tem sido realizada com outras espécies do gênero (MOCQUARD et al., 1971; CAREFOOT, 1973; Besse et al., 1975; WILlows, 1987a, 1987b; TsAi \& Chen, 1997; Furota \& Ito, 1999).

FARR (1978) analisou o comportamento social de $L$. exotica na Flórida, EUA, com breves descrições do comportamento sexual da espécie. No sul de Taiwan, TsAi \& CHEN (1997) observaram as variações nas características reprodutivas das espécies $L$. taiwanensis Lee, 1994 e $L$. exotica. Na Península Hungchun, Taiwan, TsAI \& DAI (2001), estudaram a história de vida e a estratégia reprodutiva usadas por $L$. exotica para a invasão do meio terrestre. No Brasil, Souza (1998) investigou alguns 
aspectos da biologia reprodutiva de L. exotica no Molhe do Rio Tramandaí, Imbé, Rio Grande do Sul.

Este trabalho tem por objetivo conhecer a biologia reprodutiva de $L$. exotica, verificando o período reprodutivo da espécie, época de recrutamento, fecundidade, proporção sexual e o comprimento médio de primeira maturação sexual das fêmeas em dois locais do Estuário da Lagoa dos Patos, Rio Grande, Rio Grande do Sul.

\section{MATERIAL E MÉTODOS}

A Lagoa dos Patos pode ser dividida em cinco unidades biológicas, representadas pelo Lago Guaíba, Enseada de Tapes, Lagoa do Casamento, o corpo central lagunar e o estuário, onde cada unidade é composta por águas abertas profundas e por águas rasas e protegidas (Asmus, 1998). A área estuarina da Lagoa, caracterizada por apresentar enseadas rasas e numerosas ilhas (Cordazzo \& Seeliger, 1995), mede cerca de $971 \mathrm{~km}^{2}$ de extensão e a troca de água com o Oceano Atlântico é realizada através de um canal de $20 \mathrm{~km}$ de comprimento (Bonilha \& Asmus, 1994). Apesar da dominância em extensão dos fundos moles nesta região, existe uma porção submersa de área considerável de estruturas consolidadas permanentes, como $5 \mathrm{~km}$ de rochedos do molhe leste, situados em São José do Norte e 4 km do molhe oeste, no Município de Rio Grande (CAPítoli, 1998). A área de estudo compreende o Molhe Oeste da Barra de Rio Grande ( $32^{\circ} 15,987^{\prime} \mathrm{S}$; $\left.52^{\circ} 09,783^{\prime} \mathrm{W}\right)$ e a Ilha do Leonídeo (32 $\left.02,029^{\prime} S ; 52^{\circ} 11,951^{\prime} \mathrm{W}\right)$, Estuário da Lagoa dos Patos, Rio Grande, Rio Grande do Sul, Brasil (Fig. 1).

Os exemplares de L. exotica foram obtidos através de coletas quinzenais realizadas de fevereiro/2003 a julho/ 2004 no Molhe Oeste e de maio/2003 a outubro/2004 na Ilha do Leonídeo. As coletas ocorreram no período da manhã, com uma hora de duração em cada local. Nesse intervalo de tempo, os indivíduos foram coletados

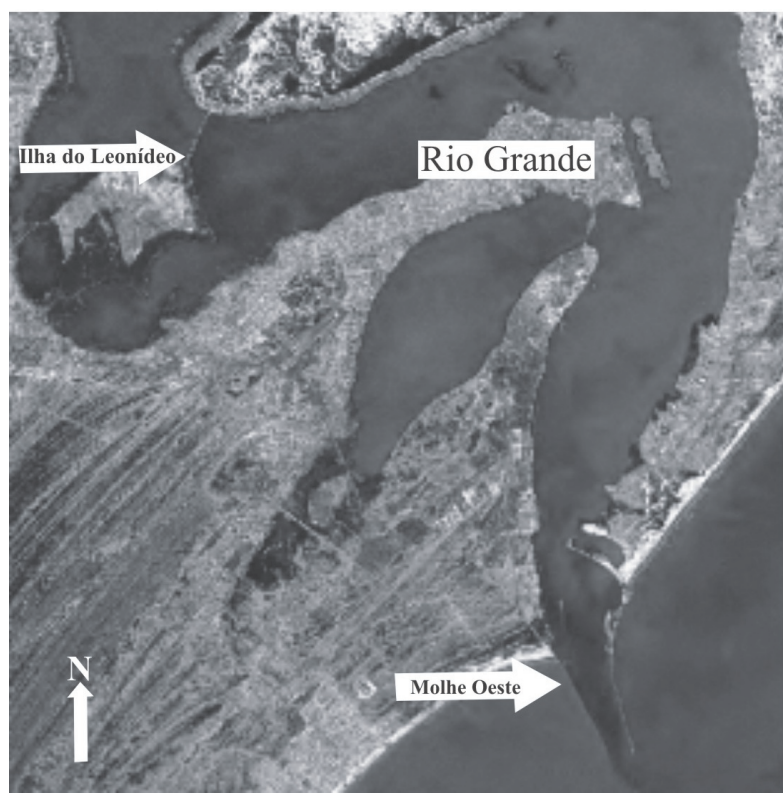

Fig. 1. Vista da área de estudo, situada no Estuário da Lagoa dos Patos, Rio Grande, Rio Grande do Sul, Brasil. manualmente por três pessoas. O material foi etiquetado e, no Laboratório de Crustáceos Decápodos, Departamento de Oceanografia, FURG, registrou-se o sexo dos indivíduos, o comprimento total em milímetros (medido da margem anterior do cefalotórax até a margem posterior do telso), o peso total em gramas e a presença de fêmeas ovígeras. Logo após, o material foi descartado. Em cada local de coleta foram tomadas as medidas de temperatura do ar e da água.

O período reprodutivo da espécie foi verificado pela presença de fêmeas ovígeras nas amostragens ao longo do tempo da pesquisa. A fim de verificar a época de recrutamento da espécie, foi registrada a presença de juvenis nas amostragens ao longo do período de estudo. Os indivíduos menores que o menor macho encontrado no Molhe Oeste $(<7,81 \mathrm{~mm})$ e na Ilha do Leonídeo $(<6,88 \mathrm{~mm})$ foram considerados juvenis, por não apresentarem os caracteres sexuais externos.

A abundância média de fêmeas ovígeras por estação do ano foi comparada através de uma análise de variância de uma via (ANOVA One-way) com nível de significância $5 \%$. No caso de diferenças significativas, um teste $a$ posteriori de Tukey foi aplicado, utilizando também nível de significância $5 \%(\mathrm{p}<0,05)$. Os pré-requisitos de normalidade e homocedasticidade foram testados e aceitos pelas rotinas de Kolmogorov-Smirnov $(p<0,2)$ e Levene ( $p>0,05)$. O mesmo procedimento foi utilizado para testar diferenças significativas entre a abundância média de juvenis ao longo das estações do ano. Para as análises sazonais, os dados foram agrupados da seguinte forma: verão (dezembro-fevereiro), outono (março-maio), inverno (junho-agosto) e primavera (setembronovembro).

Para a análise da fecundidade, foram examinadas as fêmeas ovígeras que apresentaram o marsúpio intacto. O marsúpio destas fêmeas, previamente mortas por resfriamento, foi aberto e os ovos-embriões foram contados. A relação entre o comprimento total das fêmeas ovígeras e o número de ovos-embriões contidos no marsúpio foi obtida pela aplicação de uma regressão linear. Diferenças significativas entre as declividades das duas retas obtidas a partir da regressão foram comparadas através de uma análise de covariância (ANCOVA) com nível de significância $5 \%$. Os pré-requisitos da análise de regressão linear (normalidade e homocedasticidade) também foram testados. A razão sexual foi verificada através da variação da proporção de machos em relação às fêmeas encontradas em ambas as populações durante o período de estudo.

O comprimento médio de primeira maturação $(\mathrm{CM})$ foi estimado segundo a metodologia tradicional da biologia pesqueira (KING, 1995), sendo considerado como aquele em que $50 \%$ das fêmeas apresentam ovos ou embriões no marsúpio. Para a correção da porcentagem bruta de fêmeas ovígeras, na última classe de comprimento, foi utilizado o fator de correção proposto por King (1992) apud KING (1955).

$$
\mathrm{Pi}_{\text {(ajustada) }}=1 / \mathrm{f}^{*} \text { pi }
$$

Onde $\mathrm{P}$ é a porcentagem ajustada, fé a freqüência na última classe de comprimento e pi a porcentagem de fêmeas maduras por classe de comprimento. A 
porcentagem de fêmeas ovígeras por classe de tamanho foi ajustada a uma curva logística através da minimização da soma dos quadrados dos resíduos. A equação da curva logística é dada por:

$$
\mathrm{P}=1 /\left(1+\exp \left[-\mathrm{r}\left(\mathrm{CC}_{1}-\mathrm{CM}\right)\right]\right)
$$

Onde $\mathrm{r}$ é a declividade da curva, $\mathrm{CC}_{1}$ é o limite superior da classe de comprimento e $\mathrm{CM}$ o comprimento médio de primeira maturação. As curvas logísticas de primeira maturação sexual das fêmeas foram comparadas entre os dois locais de coleta através de um teste $\mathrm{F}$ (Cerrato, 1990).

\section{RESULTADOS}

Durante o período amostral foram capturados, no Molhe Oeste, 5.376 indivíduos de L. exotica, compreendendo 1.494 juvenis $(27,79 \%), 1.748$ machos (35,71\%) e 2.134 fêmeas (39,69\%). Destas fêmeas, 245 estavam ovígeras, representando $11,48 \%$ das fêmeas. Na Ilha do Leonídeo, foram coletados 5.519 indivíduos, sendo 510 juvenis $(9,24 \%), 1.956$ machos $(35,44 \%)$ e 3.053 fêmeas $(55,32 \%)$, das quais 129 estavam ovígeras. Estas representaram $4,22 \%$ das fêmeas coletadas.

As médias de temperatura do ar variaram entre $12{ }^{\circ} \mathrm{C}$ e $25,6^{\circ} \mathrm{C}$ nos Molhes da Barra e $13^{\circ} \mathrm{C}$ e $27,5^{\circ} \mathrm{C}$ na Ilha do Leonídeo. Em relação à temperatura da água, a variação foi menor, estando entre $13,3{ }^{\circ} \mathrm{C}$ e $25,6^{\circ} \mathrm{C}$ nos Molhes e entre $13,9^{\circ} \mathrm{C}$ e $25,5^{\circ} \mathrm{C}$ na Ilha.

Período Reprodutivo. Observando-se a freqüência relativa de fêmeas ovígeras ao longo do período amostral, verifica-se que a época reprodutiva da espécie compreende os meses de outubro a primeira quinzena de junho, no Molhe Oeste e de setembro a maio, na Ilha. Nenhuma fêmea ovígera foi encontrada nos meses de julho e agosto (Fig. 2).
Embora a frequência de fêmeas ovígeras seja menor na Ilha (2,34\%) que nos Molhes (4,56\%), a distribuição destas, durante os meses de amostragem, manteve um padrão similar nos dois locais de coleta, com três picos reprodutivos, primavera, verão e outono. No entanto, os resultados do teste de Tukey, comparando o comprimento médio e abundância das fêmeas, mostram que no Molhe Oeste existe um grupo de fêmeas reprodutivas na primavera e verão e um grupo distinto no inverno. Este grupo de inverno é formado por um pequeno número de fêmeas ovígeras coletadas no início de junho (final do outono). Essas fêmeas são remanescentes do evento reprodutivo ocorrido em maio. O grupo da primaveraverão é formado por fêmeas grandes, provavelmente nascidas no ano anterior, enquanto que o grupo do outono (fêmeas coletadas no ínício de junho, que por efeito do agrupamento dos dados, acabaram sendo consideradas como um grupo reprodutivo de inverno) é formado por fêmeas pequenas, nascidas na primaveraverão (Fig. 3). Na Ilha (Fig. 4), também foram evidenciados dois grupos reprodutivos, um em setembro-outubro, formado por fêmeas grandes quando comparadas com as amostradas em março. Outro grupo pode ser identificado em março-abril, formado por fêmeas pequenas, nascidas no evento reprodutivo de setembro-outubro. O elevado desvio padrão observado no mês de abril pode ser explicado pela presença de fêmeas ovígeras nascidas durante a primavera do ano anterior (aproximadamente 8 meses de idade), coexistindo com uma coorte de menor tamanho nascida no período reprodutivo de verão (aproximadamente 4 meses).

Quando analisada a abundância de fêmeas ovígeras ao longo das estações do ano (Figs. 5, 6), observa-se que no Molhe Oeste foram coletadas mais fêmeas na primavera e menos no inverno, sendo esta diferença estatisticamente significativa (Tukey; $\mathrm{p}=0,03$ ).

\section{Molhes $\square$ Ilha}

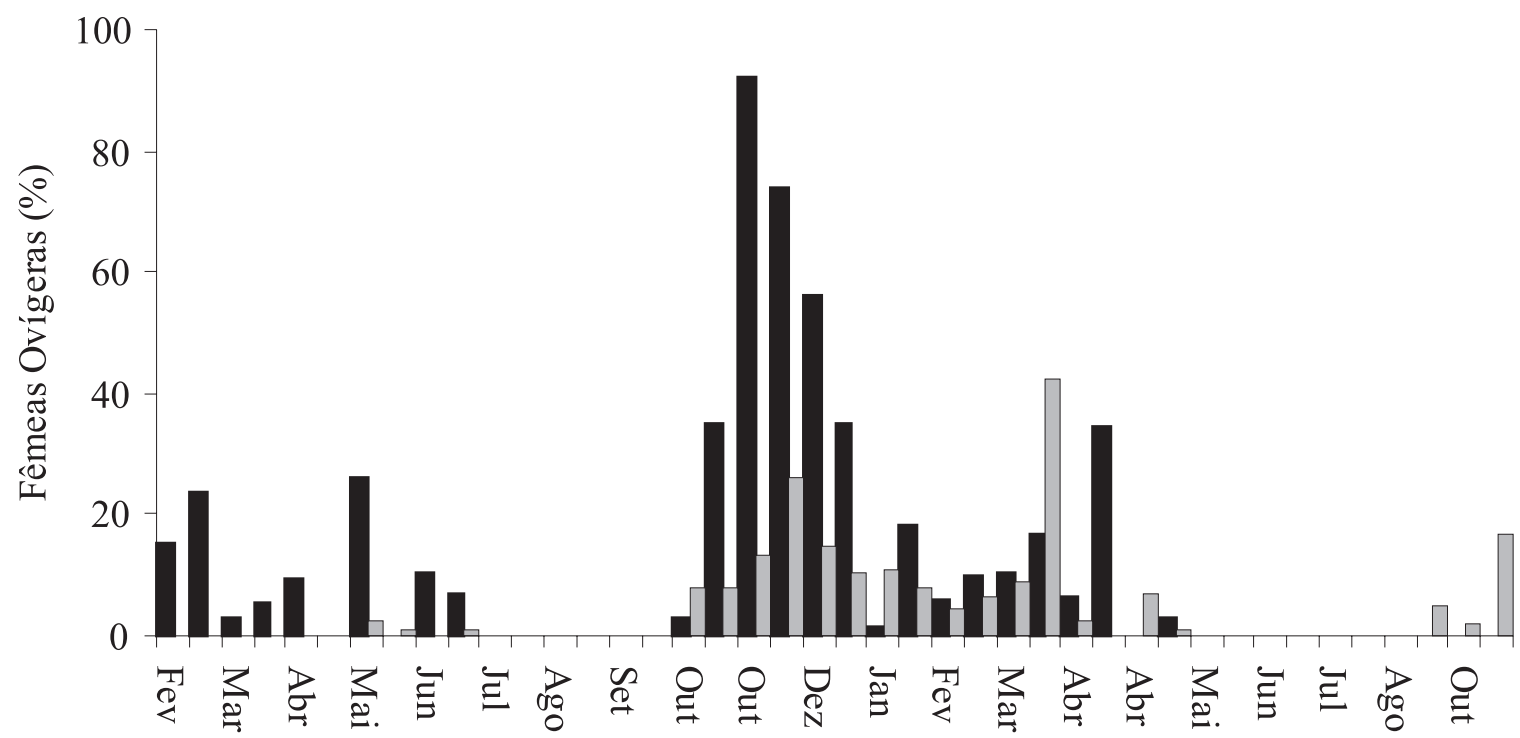

Fig. 2. Freqüência relativa de fêmeas ovígeras de Ligia exotica ao longo do período amostral, no Estuário da Lagoa dos Patos, Rio Grande, Rio Grande do Sul, Brasil. 

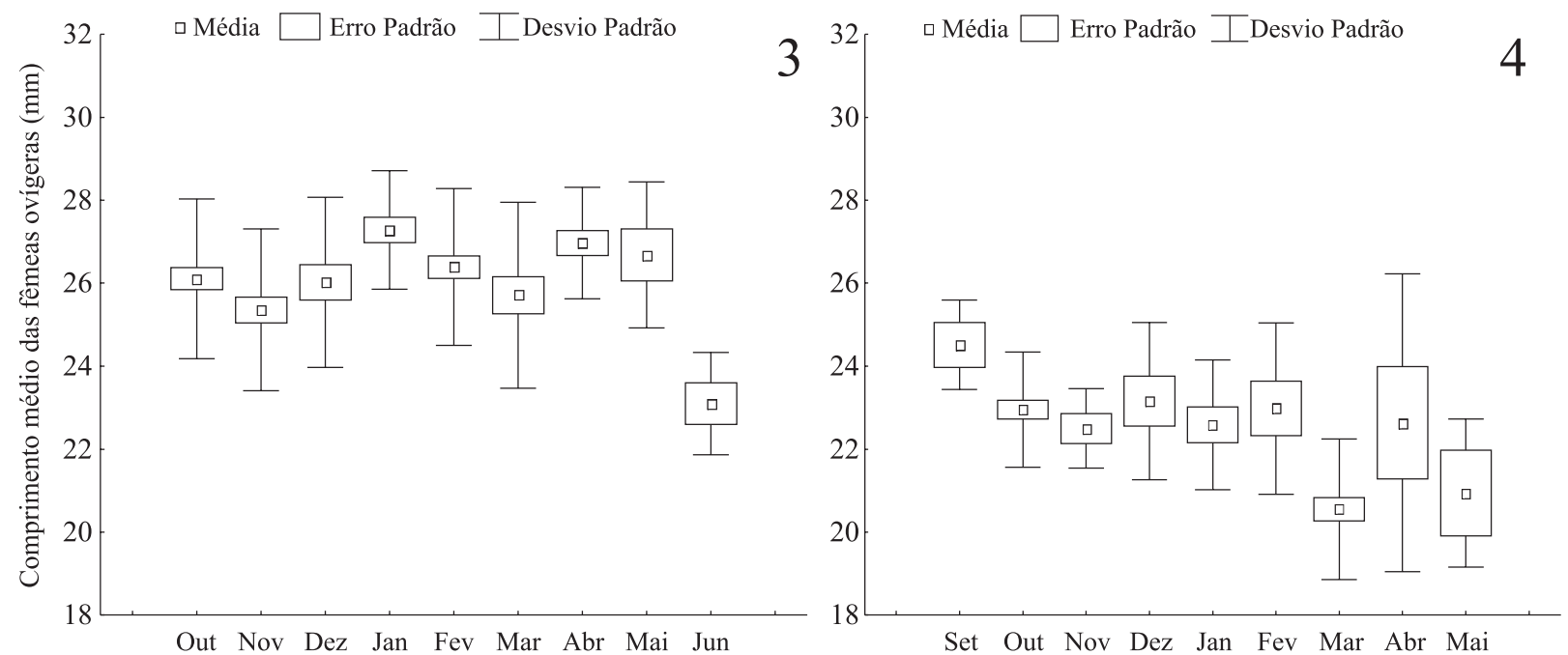

Figs. 3, 4. Comprimento médio das fêmeas ovígeras de Ligia exotica ao longo do período reprodutivo, no Estuário da Lagoa dos Patos, Rio Grande, Rio Grande do Sul, Brasil: 3, Molhe Oeste da Barra de Rio Grande; 4, Ilha do Leonídeo.
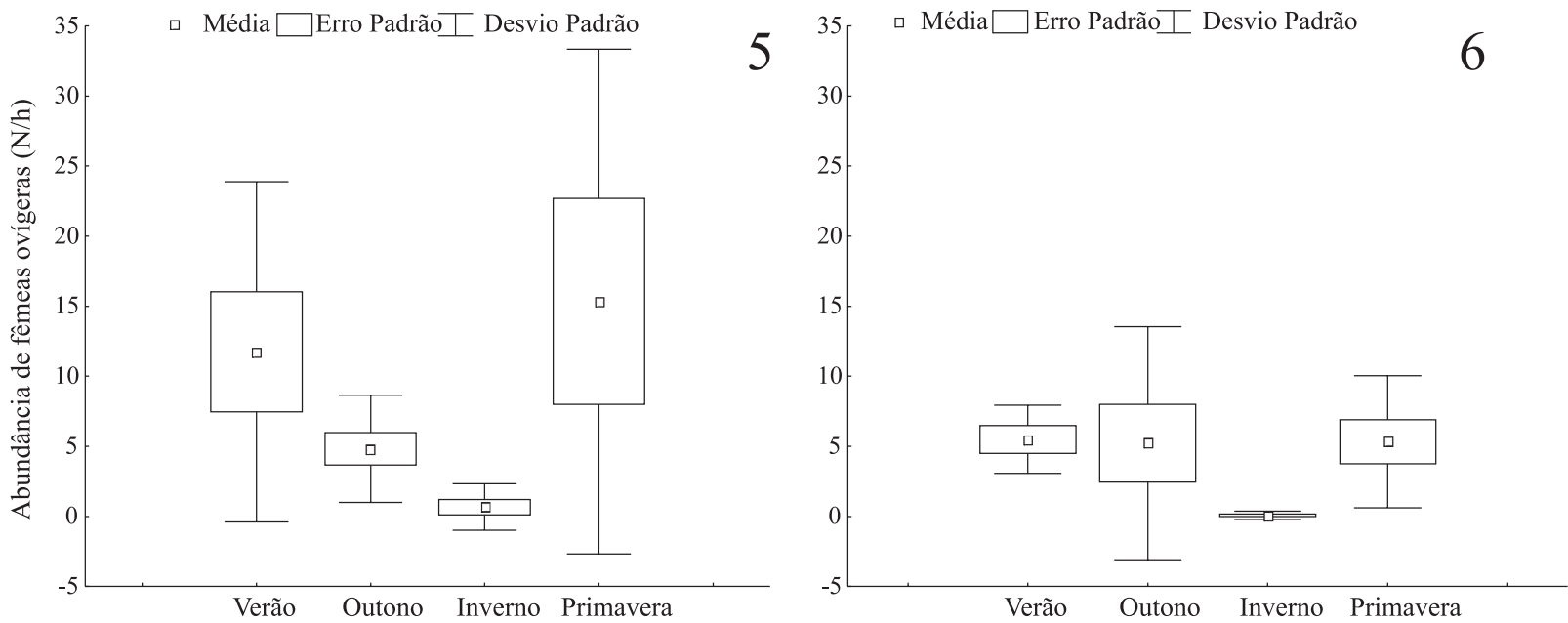

Figs. 5, 6. Abundância de fêmeas ovígeras de Ligia exotica ao longo das quatro estações do ano, no Estuário da Lagoa dos Patos, Rio Grande, Rio Grande do Sul, Brasil: 5, Molhe Oeste da Barra de Rio Grande; 6, Ilha do Leonídeo.

Na Ilha do Leonídeo não houve diferença estatística (ANOVA; $p>0,05$ ) entre o número de fêmeas ovígeras coletadas ao longo do ano, embora no inverno exista uma tendência à diminuição da abundância.

A entrada de indivíduos jovens em ambas as populações analisadas foi praticamente constante ao longo do período amostral, sendo que as maiores proporções foram registradas durante os meses de novembro a maio (Figs. 7, 8). No Molhe Oeste, a abundância de juvenis é igual ao longo das estações do ano (ANOVA; $p>0,05$ ) (Fig. 9), enquanto que na Ilha, a maior abundância de juvenis foi registrada para o verão, embora o teste aplicado não tenha detectado diferenças significativas (ANOVA; $p>0,05$ ) (Fig. 10). De qualquer forma, o recrutamento acontece com maior intensidade nos meses que seguem o período reprodutivo.

Fecundidade. Dos 5.376 indivíduos coletados no Molhe Oeste, 245 eram fêmeas ovígeras ou embrionadas. Destas, $178(72,65 \%)$ foram separadas para análise de fecundidade, por apresentarem marsúpio intacto. As fêmeas separadas para esta análise possuíam comprimento total entre 20,73 e $34,30 \mathrm{~mm}$ e o número de ovos-embriões variando entre 33 a 142 . O comprimento médio das fêmeas ovígeras e o número médio de ovosembriões foram, respectivamente, $26,02 \mathrm{~mm}$ e 88 .

Na Ilha, dos 5.519 indivíduos amostrados, 129 eram fêmeas ovígeras e 78,29\% (101) foram utilizadas para análise da fecundidade. Estas fêmeas possuíam comprimento total variando entre 17,62 e $28,61 \mathrm{~mm}$ e o número de ovos-embriões entre 25 e 113 . O comprimento médio das fêmeas ovígeras e o número médio de ovosembriões foram, respectivamente, 22,33 mm e 73,8.

Em ambas as populações, foi observada uma correlação positiva entre o tamanho das fêmeas ovígeras e o número de ovos-embriões contidos no marsúpio, de maneira que as fêmeas de maior tamanho tendem a produzir maior número de ovos-embriões. A relação está representada por uma linha reta que apresentou um valor de $\mathrm{R}^{2}$ igual a 0,93 , para os Molhes e $\mathrm{R}^{2}$ igual a 0,92 para a Ilha (Figs. 11,12). A análise de covariância demonstrou que as declividades das regressões lineares são estatisticamente diferentes $(\mathrm{p}=0,00002)$, não satisfazendo 


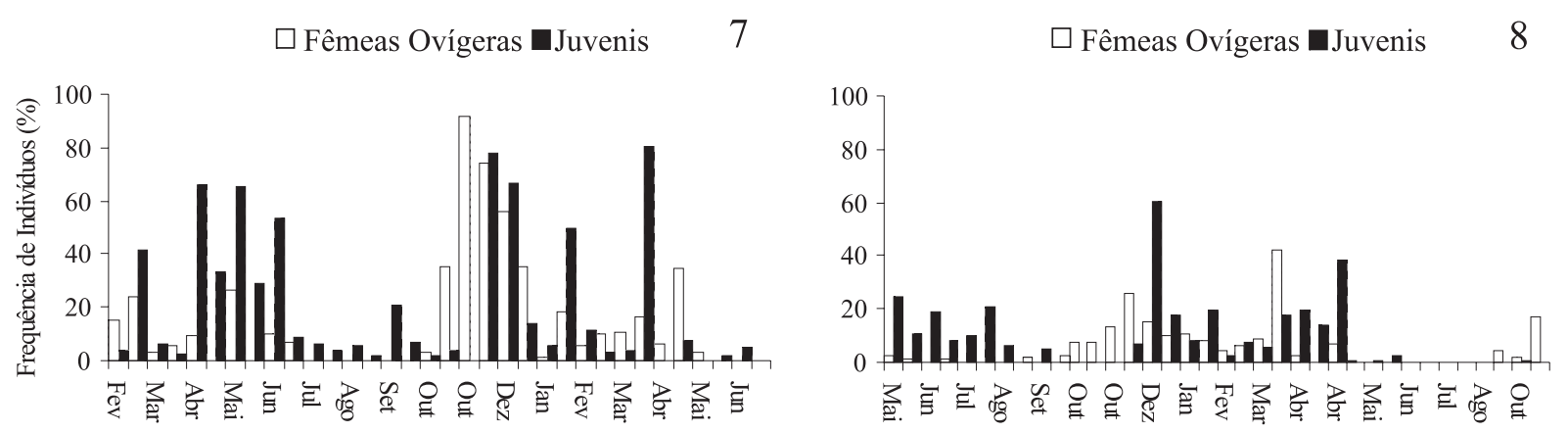

Figs. 7, 8. Freqüência relativa de fêmeas ovígeras e juvenis de Ligia exotica ao longo do período amostral, no Estuário da Lagoa dos Patos, Rio Grande, Rio Grande do Sul, Brasil: 7, Molhe Oeste da Barra de Rio Grande; 8, Ilha do Leonídeo.
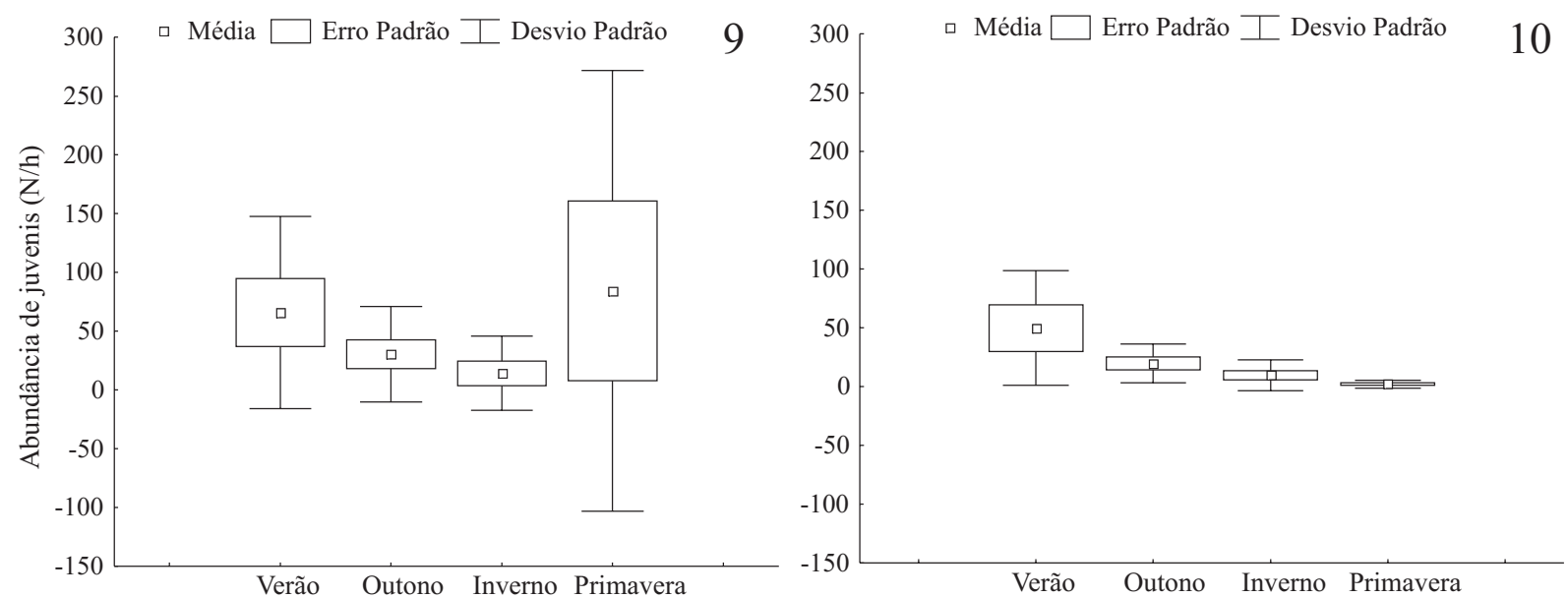

Figs. 9, 10. Freqüência de juvenis de Ligia exotica ao longo das quatro estações do ano, no Estuário da Lagoa dos Patos, Rio Grande, Rio Grande do Sul, Brasil: 9, Molhe Oeste da Barra de Rio Grande; 10, Ilha do Leonídeo.
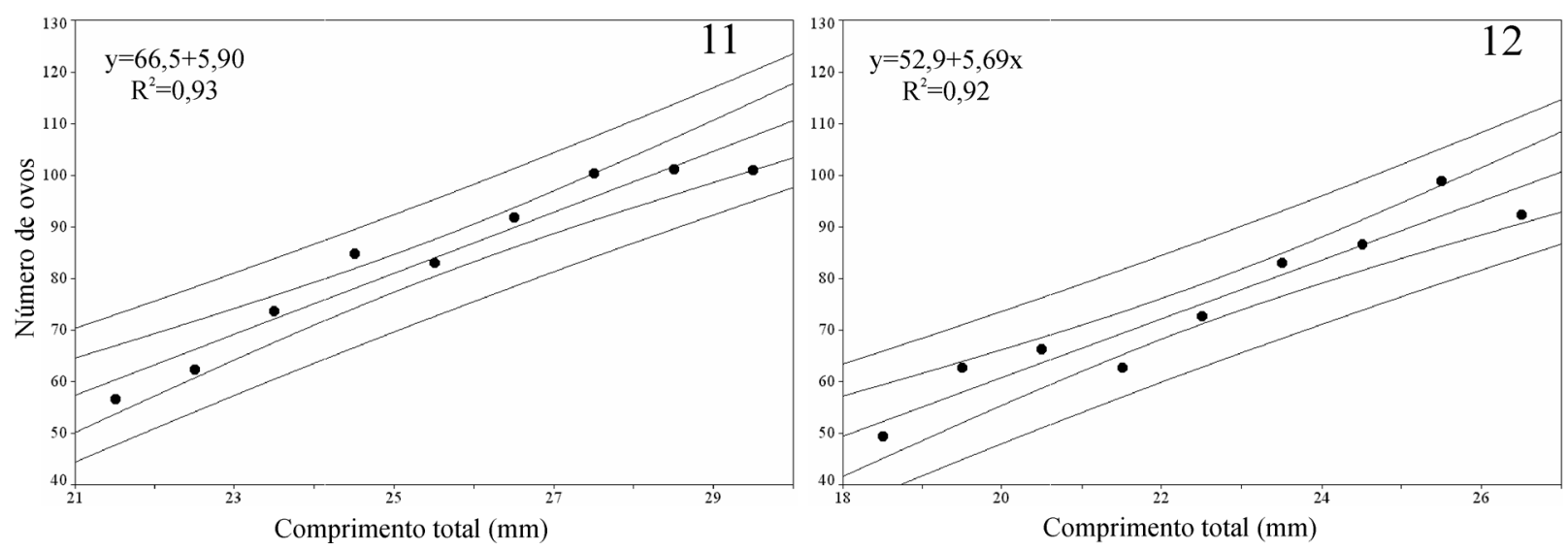

Figs. 11, 12. Relação entre o tamanho e o número médio de ovos-embriões de Ligia exotica amostrada no Estuário da Lagoa dos Patos, Rio Grande, Rio Grande do Sul, Brasil: 11, Molhe Oeste da Barra de Rio Grande; 12, Ilha do Leonídeo.

a condição de paralelismos entre elas.

Razão sexual (M:F). A razão sexual estimada para todo o período amostral mostrou um desvio a favor das fêmeas. Agrupando os dados das duas populações, a estimativa foi de 0,73 (M:F). Já os valores estimados individualmente para cada local de coleta foram $0,78 \mathrm{e}$ 0,68 para o Molhe Oeste e para a Ilha do Leonídeo, respectivamente (Fig. 13). Entretanto, variações mensais nessa relação foram observadas. No Molhe Oeste, os machos são mais representativos nas amostras durante os meses de julho, dezembro e março. Já na Ilha do Leonídeo, pode-se observar um padrão similar na variação da razão sexual, no entanto a diferença está na antecipação, na ordem de um mês, dos picos observados. Nessa localidade, os picos na razão sexual aparecem nos meses de junho e novembro.

Tamanho de primeira maturação. O comprimento médio de primeira maturação sexual de L. exotica no Molhe 


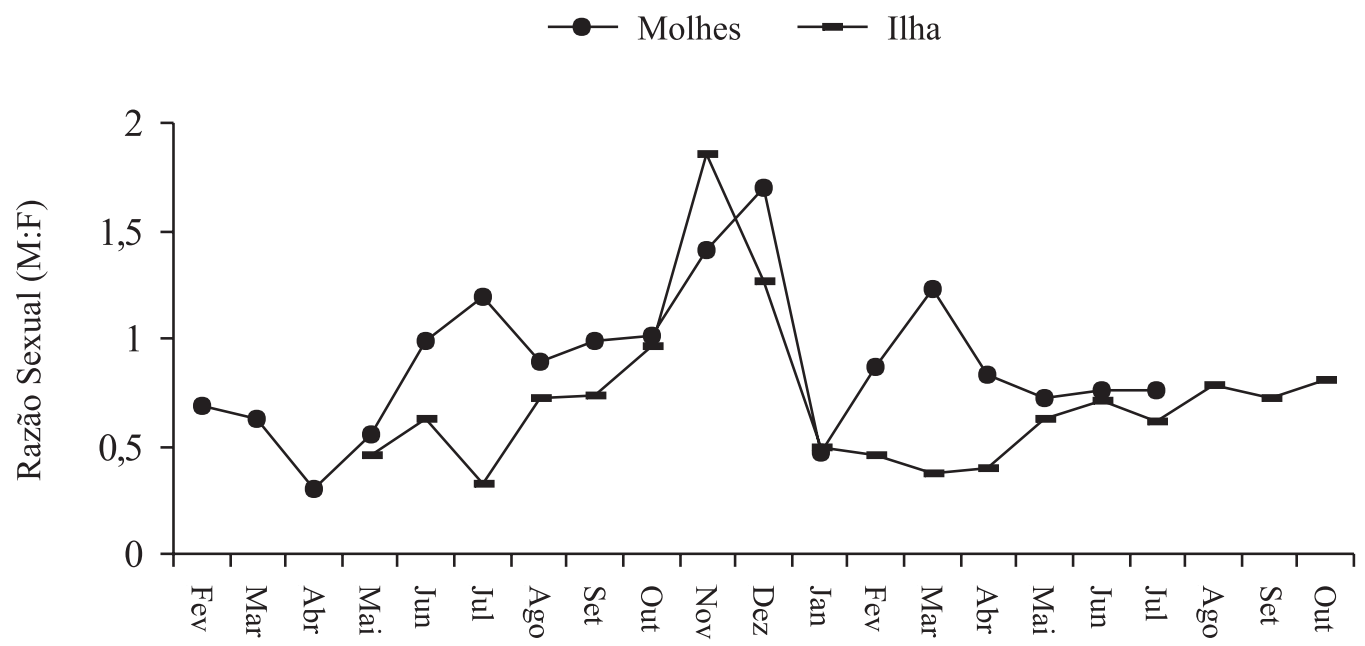

Fig. 13. Proporção de machos e fêmeas de Ligia exotica amostrados no Estuário da Lagoa dos Patos, Rio Grande, Rio Grande do Sul, Brasil.
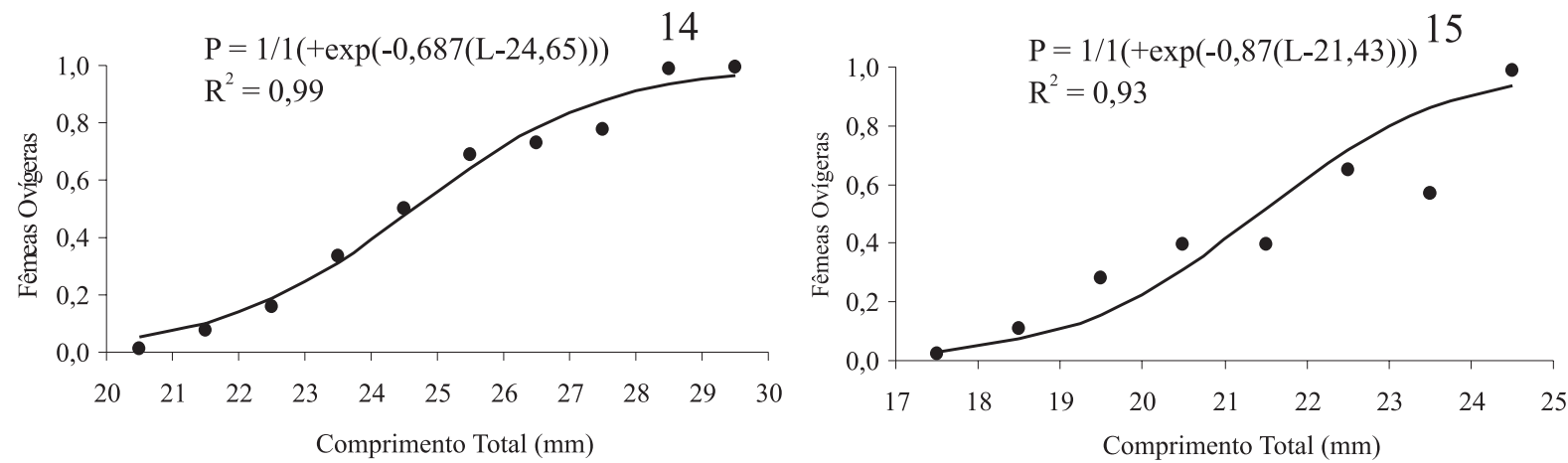

Figs. 14, 15. Comprimento médio de primeira maturação sexual das fêmeas de Ligia exotica amostradas no Estuário da Lagoa dos Patos, Rio Grande, Rio Grande do Sul, Brasil: 14, Molhe Oeste da Barra de Rio Grande; 15, Ilha do Leonídeo.

Oeste foi estimado em $24,65 \mathrm{~mm}$ de comprimento total $\left(\mathrm{R}^{2}\right.$ $=0,99)$. Nesta classe de comprimento, $50 \%$ das fêmeas estavam ovígeras (Fig. 14). Na Ilha do Leonídeo (Fig. 15), o tamanho médio de primeira maturação sexual da espécie foi estimado em $21,43 \mathrm{~mm}$ de comprimento total $\left(\mathrm{R}^{2}=\right.$ $0,93)$, significando que a espécie, no interior do estuário, inicia a reprodução com menor tamanho que nos Molhes. $\mathrm{O}$ teste $\mathrm{F}$ aplicado para a comparação das curvas logísticas indicou diferenças significativas entre ambas ( $\mathrm{F}$ crítico $=3,356 ; \mathrm{F}$ calculado $=256,658)$.

\section{DISCUSSÃO}

Muitos autores têm estudado a dinâmica reprodutiva do gênero Ligia ao redor do mundo. Diferentes padrões reprodutivos foram observados variando principalmente com a temperatura registrada no ambiente. A maioria das populações analisadas apresenta períodos reprodutivos que se estendem desde a primavera até o verão, como é o caso de L. pallasii Brandt, 1833 e $L$. oceanica Linnaeus, 1767 , analisadas no litoral do Canadá, França e Inglaterra (САREFOOT, 1973; BESSE et al., 1975; Willows, 1987a).

$\mathrm{Na}$ África do Sul, L. dilatata Brandt, 1833 apresenta período reprodutivo nos meses de primavera e verão (Koop \& FiEld, 1980). O mesmo período foi observado para a espécie $L$. cinerascens Budde-Lund, 1885, na Baía de Tóquio (Japão) (Furota \& Ito, 1999).

Para L. exotica, no Molhe do Rio Tramandaí (Imbé, RS), o período reprodutivo estende-se de setembro a abril (SouzA, 1998), terminando antes do observado para o Estuário da Lagoa dos Patos, Rio Grande.

No entanto, em Taiwan, a presença de fêmeas ovígeras de $L$. exotica foi registrada durante o ano inteiro (Tsai \& DAI, 2001), sendo este o mais longo período reprodutivo encontrado para as espécies do gênero, no ambiente.

De acordo com os dados obtidos no presente trabalho, L. exotica apresenta um período reprodutivo distinto das outras espécies do gênero, com fêmeas ovígeras observadas durante os meses de setembro a junho, equivalentes a primavera e final de outono. As diferenças encontradas em relação ao período de reprodução das demais espécies, provavelmente, são influenciadas pela temperatura local e pelas características fisiológicas e comportamentais específicas.

Em outras localidades onde foram desenvolvidos trabalhos com as espécies de gênero Ligia (CAREFOOT, 
1973; Besse et al., 1975; Willows, 1987a), se percebe que as espécies $L$. oceanica e $L$. pallassi, analisadas na Europa, pertecem a populações residentes em países com clima temperado frio, onde as temperaturas oscilam entre $3,0-20,0^{\circ} \mathrm{C}$ e por isso, o período de reprodução destas espécies fica restrito aos meses mais quentes (marçosetembro).

$\mathrm{Na}$ África do Sul e no Japão (Koop \& Field, 1980; Furota \& Iто, 1999), as espécies L. dilatata e L. cinerascens são analisadas em regiões com clima temperado quente e as temperaturas médias da primavera e verão são elevadas e semelhantes entre si, sendo também parecidas às temperaturas registradas para Rio Grande. No entanto, os meses de outono e inverno registram temperaturas muito baixas $\left(4,0-8,0^{\circ} \mathrm{C}\right)$, não fornecendo condições favoráveis à reprodução da espécie. Já em Taiwan, a temperatura é muita elevada durante todo o ano, com a mínima $\left(16^{\circ} \mathrm{C}\right)$ sendo registrada para os meses de janeiro e fevereiro (TSAI \& DAI, 2001). Desta forma, Ligia exotica, em Taiwan, mantém a reprodução durante $\mathrm{o}$ ano inteiro.

De acordo com Souza (1998), no Molhe do Rio Tramandaí, L. exotica possui dois grupos de indivíduos reproduzindo no mesmo período. O grupo que nasce em outubro reproduz em fevereiro, confirmado pelo menor comprimento médio das fêmeas. O grupo que nasce em março começa a reproduzir em setembro, continua a crescer e reproduz novamente em dezembro. Logo, o tamanho médio das fêmeas reprodutoras é maior. No Estuário da Lagoa dos Patos, estes grupos também foram observados. O grupo da primavera-verão é formado por indivíduos nascidos no ano anterior e por aqueles nascidos durante o outono, evidenciado pelo maior tamanho das fêmeas ovígeras, enquanto que o grupo do outono é formado por fêmeas pequenas, provavelmente nascidas na primavera-verão. Pode-se concluir que os eventos reprodutivos de primavera e verão são os mais importantes para a renovação da população, garantindo maior número de ovos e maior sucesso no recrutamento. Isto é comprovado pelo maior número de indivíduos jovens registrados nos meses de novembro a maio, que seguem o período reprodutivo, corroborando as informações de Koop \& FiELD (1980), os quais afirmam que o recrutamento ocorre da primavera ao outono.

Em relação à fecundidade, CAREFoOT (1973) registrou um número médio de 48 ovos e comprimento total médio das fêmeas ovígeras de L. pallasii de $22,5 \mathrm{~mm}$. Schultz (1977), analisando uma população de $L$. exotica na Georgia, não menciona o número médio de ovos-embriões, mas relata que as fêmeas ovígeras possuem comprimento total variando entre 20,0 e $22,5 \mathrm{~mm}$.

Para L. dilata, Koop \& FiELD (1980) estabeleceram a variação do comprimento total das fêmeas ovígeras entre 17,0 e $19,0 \mathrm{~mm}$, representando este o menor tamanho de fêmeas em reprodução verificado entre as espécies do gênero, sendo o comprimento mínimo semelhante ao relatado para $L$. exotica no Rio Tramandaí $(17,4 \mathrm{~mm})$ (SouzA, 1998) e na Ilha do Leonídeo (17,62 mm).

$\mathrm{O}$ comprimento médio das fêmeas ovígeras de $L$. exotica (22,0 mm) e o número médio de ovos-embriões (80), relatados por Souza (1998), incluem-se dentro da variação encontrada em Rio Grande, uma vez, que no Molhe Oeste, estes valores são maiores $(26,02 \mathrm{~mm}$ e 88 ovos-embriões) e na Ilha do Leonídeo são menores (22,33 mm e 73,8 ovos-embriões). Willows (1987a) menciona que a fecundidade de L. oceanica foi estatisticamente menor na população menos exposta à ação do mar. Este resultado está de acordo com o observado no presente estudo, já que, quando se compara a fecundidade entre as mesmas classes de tamanho para os dois locais amostrados, pode-se observar um maior incremento de ovos por unidade de tamanho na população do Molhe Oeste. Porém, quando se inclui todas as classes de tamanho na análise isso não se verifica. Essa constatação pode ter sido causada pela ausência de fêmeas grandes nas amostras da Ilha do Leonídeo, o que torna difícil a comparação entre os locais. A ausência de fêmeas grandes na Ilha se dá por um padrão diferencial de crescimento entre as populações, de maneira que as fêmeas dos Molhes apresentam comprimentos máximos maiores que na Ilha. Como regra geral, a taxa de incremento no número de ovos por classe de comprimento tende a diminuir à medida que esse aumenta. Dessa forma, a ausência de fêmeas maiores na Ilha do Leonídeo pode ter forçado a declividade da reta para cima.

O comprimento médio de primeira maturação sexual das fêmeas de L. exotica no Estuário da Lagoa dos Patos, Rio Grande, também varia em relação ao ambiente. No Molhe Oeste, as fêmeas atingem a maturidade sexual com 24,65 mm, enquanto que na Ilha do Leonídeo as fêmeas chegam à maturidade com 21,43 mm de comprimento total. Souza (1998) estimou que o tamanho de primeira maturação sexual das fêmeas está entre as classes de 20,0 a 22,5 mm de comprimento total.

Em relação à variação no número de machos e fêmeas durante o período amostral, nota-se que o número de fêmeas é maior que o de machos. No entanto, durante os meses de novembro e dezembro existe um maior número de machos, em ambas as populações analisadas. Provavelmente este aumento esteja relacionado ao evento reprodutivo. As fêmeas morrem devido ao elevado gasto com energia na reprodução, uma vez que estas carregam os ovos-embriões no marsúpio durante todo o desenvolvimento pós-embrionário dos indivíduos, dispondo abrigo, proteção e suprimento alimentar à prole (Sutton, 1980). A mortalidade diferencial entre os sexos parece afetar também a queda do número de fêmeas em maio e junho na Ilha do Leonídeo, estando relacionada com o pico reprodutivo registrado para o mês de março.

As duas populações de $L$. exotica analisadas no Estuário da Lagoa dos Patos podem ser consideradas distintas, no que diz respeito às características reprodutivas da espécie, diferindo principalmente no tamanho de primeira maturação sexual das fêmeas, que apresentou valores menores na população mais afastada do mar e na fecundidade por tamanho.

A análise das retas de fecundidade permite afirmar que a espécie está mais bem adaptada para a reprodução no ambiente marinho, já que a taxa de incremento do número de ovos por classe de tamanho é significativamente maior nesse local.

A diferença entre os tamanhos das fêmeas pode ser influenciada pelo estresse ambiental, causado pelas 
oscilações bruscas de salinidade na Ilha. Este local está situado no interior do estuário, cercado por águas que chegam a apresentar salinidade de 0,3 ppt. Com a entrada de água marinha no estuário e a escassez de chuvas, esta salinidade pode chegar a $30 \mathrm{ppt}$. O Molhe Oeste é cercado, do lado interno, por águas estuarinas, com salinidades registradas entre $0,3-30,0 \mathrm{ppt}$, e do lado externo, pelo Oceano Atlântico, onde a salinidade mantém-se em torno de 30,0 ppt. Assim, a espécie não sofre as grandes variações de salinidade.

Desta forma, na Ilha do Leonídeo, é possível que a população reproduza mais cedo, como uma estratégia de sobrevivência da espécie. Como uma espécie tipicamente halófila, L. exotica habita áreas próximas ao ambiente marinho, as quais se tornam mais adequadas para a sobrevivência e a manutenção da população.

Agradecimentos. Aos colegas do Laboratório de Crustáceos Decápodos (FURG), pelo auxílio nas saídas de campo e à Capes pela concessão de bolsa de doutorado à primeira autora. Ao Programa de Pólos de Modernização Tecnológica da Secretaria de Ciência e Tecnologia do Estado Rio Grande do Sul, pelo apoio financeiro.

\section{REFERÊNCIAS BIBLIOGRÁFICAS}

Asmus, M. L. 1998. A Planície Costeira e a Lagoa dos Patos. In: Seeliger, U.; Odebrecht, C. \& Castello, J. P. eds. Os ecossistemas costeiro e marinho do extremo sul do Brasil. Rio Grande, Ecoscientia. p.9-12.

Besse, G.; Picaud, J-L \& Mocquard, J-P. 1975. Étude d'une population de Ligia oceanica L. (Crustacé Isopode) de la Cote Charentaise. II. Le cycle de reproduction et les variations saisonnières de la biomasse. Bulletin of Ecology 6(2):6778

Bonilha, L. E. \& Asmus, M. L. 1994. Modelo ecológico do fitoplâncton e zooplâncton do estuário da Lagoa dos Patos, R.S. Publicações da Academia de Ciências do Estado de São Paulo 87(1):347-362.

Capítoli, R. 1998. Substratos consolidados. In: Seeliger, U.; Odebrecht, C. \& Castello, J. P. eds. Os ecossistemas costeiro e marinho do extremo sul do Brasil. Rio Grande, Ecoscientia. p.96-99.

Carefoot, T. H. 1973. Studies on the growth, reproduction, and life cycle of the supralittoral isopod Ligia pallasii. Marine Biology 18(4):302-311.

Carefoot, T. H. \& TAYloR, B. E. 1995. Ligia: a prototypal terrestrial isopod. In: Alikhan, M. A. ed. Terrestrial Isopod Biology. Balkema, Rotterdam, p.47-60.

Carefoot, T. H.; Taylor, B. E. \& Brett, K. 1998. A day in the life of an isopod: time and energy allocations in the semiterrestrial Ligia pallasii. Israel Journal of Zoology 44:463-471.

Cerrato, R. M. 1990. Interpretable statistical tests for growth comparisons using parameters in the von Bertalanffy equation. Canadian Journal of Fisheries and Aquatic Sciences 47:1416-1426.

Cordazzo, C. V. \& Seeliger, U. 1995. Guia ilustrado da vegetação costeira no extremo sul do Brasil. Rio Grande, Editora da FURG. 275p.

FARR, J. A. 1978. Orientation and social behavior in the supralitoral isopod Ligia exotica (Crustacea: Oniscoidea). Bulletin of Marine Science 28(4):659-666.

Furota, T. \& Ito, T. 1999. Life cycle and environmentally induced semelparity in the shore isopod Ligia cinerascens (Ligiidae) on a cobble shore along Tokyo Bay, Central Japan. Journal of Crustacean Biology 19(4):752-761.

Hama, N.; Okada, Y.; Pollak, E.; Molnar, L. \& NiIda, A. 2003. Peripheral targets of centrally located putative acessory neurons of MRO in the isopod Ligia exotica. Journal of Experimental Biology 206(15):2619-2698.

Hariyama, T.; Tsukahara, Y. \& Meyerrachow, V. B. 1993. Spectral responses including UV-sensitive cell-type in the eye of the Ligia exotica. Naturwissenschaften 80(5):233-235.

Hariyama, T.; Meyerrachow, V. B.; Kawauchi, T.; Takaku, Y. \& Tsukahara, Y. 2001. Diurnal changes in retinula cell sensitivities and receptive fields (two dimensional angular sensitivity functions) in the apposition eyes of Ligia exotica (Crustacea, Isopoda). Journal of Experimental Biology 204(2):239-248

KING, M. G. 1995. Fisheries biology, assessment and management. Oxford, Fishing News Books. 340p.

Koop, K. \& Field, J. G. 1980. The influence of food availability on population dynamics of a supralittoral isopod, Ligia dilatata Brandt. Journal of Experimmental Marine Biology and Ecology 48:61-72.

Lemos de Castro, A. 1971. Isópodos terrestres introduzidos no Brasil (Isopoda, Oniscoidea). Boletim do Museu Nacional 282:1-14.

Mocquard, J-P.; Besse, G.; Juchault, P.; Legrand, J-J.; Maissiat, J. \& Noulin, G. 1971. Contribution a l'analyse du controle neurohumoral de la croissance, de la mue et de la physiologie sexuelle male et femelle chez l'oniscoide Ligia oceanica L. (Crustacé, Isopode). Annals of Embriology and Morphology 4(1):45-63

Schultz, G. A. 1977. Terrestrial isopods crustaceans (Oniscoidea) from St. Catherines Islands, Georgia. Georgia Journal of Science 35:151-158.

SouzA, G. D. 1998. Biologia reprodutiva de Ligia exotica (Crustacea, Isopoda, Ligiidae) no Molhe do Rio Tramandaí, Imbé, Rio Grande do Sul, Brasil. Iheringia, Serie Zoologia, (84):101-108

SouZA-Kury, L. A. 1998. Malacostraca-Peracarida. Isopoda. Oniscidea. In: Young, P. S. ed. Catalogue of Crustacea of Brazil. Rio de Janeiro, Museu Nacional, p.653-674.

Sutton, S. L. 1980. Woodlice. Oxford, Perganon. 143p.

Tsai, M. C. \& ChEN, H. C. 1997. Variations of reproductive traits of two semiterrestrial isopods Ligia exotica and Ligia taiwanensis (Crustacea: Ligiidae) in southern Taiwan. Zoological Studies 36(1):33-41

TsaI, M. C \& DAI, C. F. 2001. Life history plasticity and reproductive strategy anabling the invasion of Ligia exotica (Crustacea: Isopoda) from the littoral zone to an inland creek. Marine Ecology Progress Series 210:175-184.

Tsai, M. C.; Dai, C. F \& Chen, H. C. 1997. Responses of two semiterrestrial isopods Ligia exotica and Ligia taiwanensis (Crustacea) to osmotic stress. Comparative biochemistry and physiology, part A: Physiology, 118(1):141-146. 1998. Desiccation resistance of two semiterrestrial isopods Ligia exotica and Ligia taiwanensis (Crustacea) in Taiwan. Comparative biochemistry and physiology, part A: Molecular \& Integrative Physiolgy, 119(1):361-367.

Willows, R. I. 1987a. Population dynamics and life history of two contrasting populations of Ligia oceanica (Crustacea: Oniscidea). Journal of Animal Ecology 56:315-330 1987b. Intrapopulation variation in the reproductive characteristics of two populations of Ligia oceanica (Crustacea: Oniscidea). Journal of Animal Ecology 56:331-340

Yamagishi, H.; Takano, S. \& Tanaka, K. 2004. Dual effects of dopamine on the adult heart of the isopod crustacean Ligia exotica. Zoological Science 21(1):15-21. 